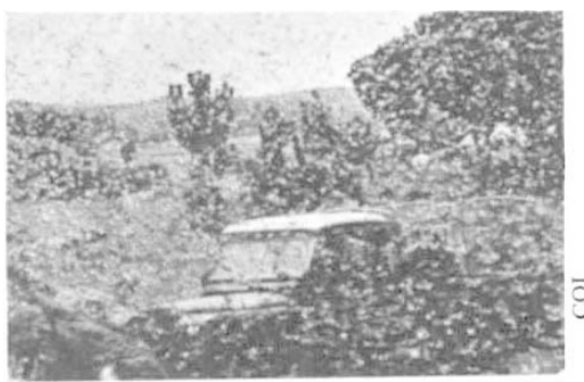

Swarm conditions, and the culprit in close-up (right)

\section{Locusts: vigilance still needed}

SuCH is the decline in surveying and reporting the activities of the desert locust (Schistocerca gregaria) that the precise significance of recent increased breeding of this dangerous insect cannot yet be estimated. It does seem that despite the somewhat alarming press releases put out earlier this year by FAO-which plays an overall, coordinating role in desert locust control -locust breeding in the Horn of Africa does not appear to have been on the scale expected. The reports made to the recent meeting of the Council of the East African Desert Locust Control Organisation in Arusha indicate that the threat of a major upsurge of Schistocerca is less imminent than at one time seemed likely.

There appear still to be some breeding swarms around the southern Red Sea and the Gulf of Aden, particularly on the coast of Somalia and in the tip of the Arabian Peninsula, and a few swarms have been observed crossing the frontier from Ethiopia into Sudan. This last country, however, is one of the best equipped and most efficient at dealing with this sort of threat, which seems to have been tackled promptly. Less certain is the situation in Ethiopia itself and in Eritrea, where under present conditions of intensifying military activity, locust surveying is extremely difficult, if not impossible. However, it has been reported that not only have both the Ethiopian, and the rebel Eritrean commands permitted the operation of some survey parties, but the Eritreans have also enabled a certain amount of control to be carried out.

Experts at the COPR in London reckon that most of the swarms in those areas that it has been possible to visit, have now been controlled, and there may in fact not have been much breeding in Eritrea itself. It is pointed

\section{Sorry, for copyright reasons some images on this page may not be available online}

out that this will have been winter breeding (which is what sparked off FAO's alarm earlier this year), and any resultant swarms, which would normally move out of this Eritrean breeding area, would by now have been reported from neighbouring countries. That no such reports have been received is a possible indication that the danger has receded, at least for the moment, and it is felt that the present pattern of breeding, as indicated by such reports as are available, is actually less widespread than that in January and March.

Despite this rather reassuring picture, there can still be no relaxation of control measures against such swarms and hopper bands as can be located, nor of vigilance over the whole desert locust area. Even in times of comparative recession-and it is 16 years since the last considerable outbreakthere are endemic solitary phase Schistocerca virtually the whole way across the northern half of Africa, and as far cast as Afghanistan and Pakistan. Increasing swarms have been reported within the past two seasons in Libya, in the Yemen and in Saudi Arabia, and what are referred to as "low density scattered adults" in various areas under regular survey in Pakistan. 'This phrase may mean anything up to 1,000 insects per square kilometre, providing a nucleus from which breeding could cause a local outbreak rapidly if conditions are good and the first signs of swarming do not lead to rapid action.

The danger may lie in poor reporting leading to action coming too late. This is particularly so in the region where there is at present cause for concern, since it is here, in the central sector of the locusts' range and where with good rains, three generations are possible in a year, that the risk of swarming is always the greatest. Both COPR in London, and FAO at its Rome headquarters, have noticed that whereas a few years ago locust officers in the field, and those responsible for surveyance in a number of countries, used to return complete report forms, filled in with every detail of importance, now - 16 years after the big swarms-only casual reports are received, often incomplete and frankly inadequate. At a time such as the present, when there are known to be good conditions for the rapid breeding that leads to swarming, this is especially dangerous.

Much depends on weather conditions, which may be the factor deciding whether swarms in the Red Sea area migrate into central Saudi Arabia and thence on across the Gulf into Iran and Pakistan, or westwards into Sudan, across the Sahara and on to North Africa. That no one can survey all the area is evident: within the last few days, a message from the British Embassy in Sana'a brought a report of numerous small swarms in Eastern Yemen, where there has been no reported locust activity for many yearsand this was not seen by locust control personnel, but apparently by a British official on some quite separate mission.

One thing which has made up for the poor quality of ground reporting is the increasing use of modern aerial remote sensing techniques. Infra-red photography from Landsat, combined with the data from meteorological satellites operating over the same regions, makes it possible to gain a very precise idea of the increase and type of vegetation in remote desert areas, in as small a parcel of land as 2 square kilometres. This can prove the most valuable early warning system available to those whose business it is to collect and collate material from all over the enormous area of potential locust brecding. The system is only in its infancy, but its possibilities are very great. In the words of a COPR locust officer, "there is no 'plague' at the moment. But the ingredients are there. What happens next depends on the weather, and on the efficacy of survey and control". Meanwhile, stocks of insecticides in some Red Sea countries, exhausted by the end of the winter breeding season, are bcing replenished through FAO's technical cooperation programme. $\$ 800,000$ have been allocated to Sudan, the Yemen and Somalia for this purpose and for renewal of equipment. Britain has provided the Desert Locust Control Organisation with two new spraying aircraft and has also virtually renewed the organisation's fleet of land rovers for ground operation.

Peter Collins 